Research Article

\title{
A Survey on Mental Wellbeing among Indian Population during Lockdown-2 of COVID-I9 Pandemic
}

\author{
Dixu Sharma', Manjry Anshumala Barla ${ }^{2}$, Yogita Munjal $^{3}$, Rakesh Roushan $^{4}$ \\ ${ }^{1}$ PG Scholar, ${ }^{4}$ Assistant Professor, PG Department of Kriya Sharir, CBPACS, Under Govt. of NCT Delhi, New Delhi, India. \\ ${ }^{2}$ Senior Medical Officer (Ay.), , ${ }^{3}$ Deputy Director, Directorate of AYUSH, Govt. of NCT Delhi, New Delhi, India. \\ DOI: https://doi.org/10.24321/2455.7048.202109
}

I $\quad \mathbf{N} \quad \mathbf{F} \quad \mathbf{O}$

\section{Corresponding Author:}

Rakesh Roushan, PG Department of Kriya Sharir, CBPACS, Under Govt. of NCT Delhi, New Delhi, India.

E-mail Id:

rakesh.roushan45@delhi.gov.in

Orcid Id:

https://orcid.org/0000-0002-0874-0332

How to cite this article:

Sharma D, Barla MA, Munjal Y, Roushan R. A Survey on Mental Wellbeing among Indian Population during Lockdown-2 of COVID-19 Pandemic. Epidem Int. 2021;6(3):20-26.

Date of Submission: 2021-09-09

Date of Acceptance: 2021-09-26
$\begin{array}{llllllll}\mathbf{A} & \mathbf{B} & \mathbf{S} & \mathbf{T} & \mathbf{R} & \mathbf{A} & \mathbf{C} & \mathbf{T}\end{array}$

Introduction: COVID-19 emerged as a global pandemic and its disastrous effects have been felt all over the world. In India, people faced two phases of lockdown. The Government imposed several restrictions on the residents which increased temporary unemployment for many workers. The pandemic has caused a serious impact on the mental health of the people. This survey was done on the verge of lockdown-2, by using DASS-42 scale questionnaire. The aim of this present study was to access the effect of lockdown-2 on mental wellbeing in the Indian population.

Methods: It was a study conducted during the second wave of COVID-19 via an online survey using DASS-42 scale questionnaire in the Google Forms bilingually. The outcome of the questionnaire was the assessment of the degree of depression, anxiety, and stress on Likert scale.

Results: 170 individuals participated in this study. All participants experienced stress, anxiety and depression during lockdown. The results revealed that the lockdown affects psychological health of people. There was no association between men and women in terms of the degree of depression, anxiety, and stress on Likert scale.

Conclusion: During the second lockdown in India due to the COVID-19 pandemic, the residents suffered from a moderate level of depression, moderate level of stress, and mild level of anxiety. It is also evident that different age groups have experienced a psychological impact of the pandemic. The outbreak of this pandemic indicates the need to pay greater attention to mental health to prevent and diminish the psychological outcomes of the pandemic.

Keywords: Anxiety, COVID-19, DASS-42 scale, Depression, Lockdown-2, Stress 


\section{Introduction}

Mental health is important to our overall wellbeing and it is as important as physical health. ${ }^{1}$ Good mental health increases our efficiency, and enables us to enjoy our free time, and make an effective contribution to society. A novel coronavirus (2019-nCoV) caused COVID-19 that spread rapidly around the globe and on the 30th of January, 2020, the World Health Organization declared an international health emergency. ${ }^{2}$ In response to this global health emergency, in India, the first complete lockdown was implemented on 24th March 2020. During this Phase-1 (25th March-14th April 2020), nearly all services and workshops were suspended.

Numerous restrictions were imposed in the lockdown in order to ensure a decrease in the rate of spread of the virus. These restrictions had a huge impact on the life of people. Public transport facilities such as buses, trains, metro services, and airways had been completely stopped which in turn made it difficult for people all over the country to travel from one place to another.

The Government imposed several restrictions on the residents which increased temporary unemployment for many workers. People were forced to stay at home and limited visit to work places reduced the interaction of people with each other. A sudden decrease in mechanical and business exercises was seen during this unexpected lockdown. Quarantine with family, friends, and colleagues was imposed. The fearful outcome of COVID-19 disease was pervasive among the people.

All these changes added distress among the public and were related to unfavourable mental wellbeing ramifications. Research studies found out that exceptional circumstances of detention have caused psychological effects including higher levels of anxiety and stress. ${ }^{3}$ These uncertain conditions are also considered as triggering elements for anxiety and depression in certain population sub-groups. ${ }^{4}$ The isolation from society during lockdown caused mental and physical health issues and it is also evident that psychological health issues are more common in people who are in quarantine. ${ }^{5}$ This article sheds light on the effect of isolation and lockdown due to the COVID-19 pandemic on the mental wellbeing status of an individual.

Even though there were job and income-related issues in different sectors during lockdown-1, it was found that people were more enthusiastic, happy and excited. They enjoyed home quarantine and being with family. No doubt there were a lot of challenges but people were not in that much state of mental stress as we observed from the community and different social media platforms. During the 2nd Wave of COVID-19, it was observed that people were less enthusiastic and happy.
Smart devices have been innovated a lot. These initiatives have turned mobile apps into an advantageous, simple to utilise, and less tedious technique to collect data from the target population. In the absence of recorded health administration data, self-reported wellbeing status and health care service use are the required indicators needed to assess the performance and attitude of any health system. ${ }^{6}$

Google Forms-based study has various advantages such as lower cost, usability for participants, ease of analysis, better response rates, greater flexibility, assurance of user anonymity and preferences, and faster data synthesis related to conventional epidemiological and observation strategies.

There is little data regarding the effect of complete lockdown due to the COVID-19 pandemic on the psychological status of a person. Consequently, the objective of this survey was to study the effect on mental wellbeing among the Indian population during the complete shutdown.

\section{Methods}

\section{Study Design}

This is a cross-sectional analysis of data, produced using the Google Forms through a pre-structured questionnaire (DASS-42), and was conducted between May 15 and June 15, 2021. It was circulated using a web-based Google Forms link via social media platforms such as WhatsApp, Twitter accounts, Facebook pages and Instagram, and it was requested to pass it on to others. The outcome of the participant's responses was inevitably recorded in the excel sheet. The option for voluntary participation in the study was provided in the Google Form. It was made clear that by participating in the survey, users were voluntarily giving their consent to use the data for research purposes. We followed the Strengthening the Reporting of Observational Studies in Epidemiology (STROBE) guidelines to report the findings. ${ }^{7}$

\section{Study Setting \\ Sociodemographic Factors}

It included variables such as age, gender, income, social affiliation, geographical region etc.

\section{Stress, Anxiety and Depression}

To examine mental health, DASS- 42 (depression, anxiety and stress scale) was used. It comprises 42 questions to assess depression, anxiety and stress. This scale assesses three negative emotional states in an individual. These feelings were rated on a 4-point Likert scale which ranges from 0 to 3: It did not apply to me at all - 0 , It applied to me to some degree or some of the time - 1 , It applied to me to a considerable degree or a good part of time - 2 , It applied to me very much or most of the time - 3 . The 
sum of scores of depression, anxiety and stress were then further categorised and classified.

In the calculation of Chi-square test, 3 cells had an expected count of less than 5 , so to avoid error, we merged severe and very severe cases in the category of severe cases only.

\section{Participants}

The sample consisted of 170 study participants. It included all individuals who were 18 years old and above. All the residents of India who had a smartphone, tablet, or any other such gadget, and who were willing to download the specific Google Form and provide the essential data to the questionnaire willingly in either English or Hindi were eligible to take part in the study.

\section{Data Sources and Data Collection Methods}

The Google Forms was declared and advanced through online media platforms such as Twitter accounts, Instagram, and Facebook. The questionnaire in the Google Forms was finalised by shared conversations with specialists, followed by iterative defining and refining, and included multiple-choice questions, modified Likert scales, and dichotomous alternatives. The questionnaire was not open-ended and was simple, easily comprehensible, launched bilingually in English and Hindi according to the World Health Organization's guidance for translation and adaptation of instruments. ${ }^{8}$

\section{BIAS}

Google Forms was promoted across social media platforms for a wider reach among all geographic and socioeconomic strata. Yet, the data are not representative of the population, as the respondents were confined to individuals who are smartphone users, more active on the web and those who are already on social media platforms.

\section{Study Tool}

This is a self-administered survey that helps in assessing and diagnosing the mental health status or presence of depression, anxiety and stress of individuals which they had experienced during the COVID-19 outbreak during lockdown-2 in India. This survey collected the demographic details in addition to forty-two questions related to the mental wellbeing of the respondents with their consent. The reactions to evaluate their mental wellbeing were classified as mild, moderate, and severe cases using DASS Questionnaire (DASS)-42. The suggested cut-off scores for conventional severity labels (normal, moderate, severe) are as shown in Table 1.

\section{Statistical Analysis}

The qualitative data recorded through the Google Form of DASS-42 questionnaire were automatically imported into an Excel sheet (Microsoft Corporation). Numerical codes were allocated to all the options for each question in the questionnaire. Statistical Package for Social Sciences (SPSS) version 22 was used to analyse the data. This coded Excel document was then brought into SPSS V.22 and used for statistical analysis. For categorical data, descriptive statistics were reported by using frequencies and percentages. Chisquare test was used to access the association between categorical variables. P-value $<0.05$ was considered significant.

Table I.DASS-42 Scoring Method"

\begin{tabular}{|c|c|c|c|}
\hline Subscale & Depression & Anxiety & Stress \\
\hline Normal & $0-9$ & $0-7$ & $0-14$ \\
\hline Mild & $10-13$ & $8-9$ & $15-18$ \\
\hline Moderate & $14-20$ & $10-14$ & $19-25$ \\
\hline Severe & $21-27$ & $15-19$ & $26-33$ \\
\hline Extremely Severe & $28+$ & $20+$ & $34+$ \\
\hline
\end{tabular}

\section{Result}

\section{Sociodemographic Profile of the Respondents}

A total of 170 respondents participated in the survey; of these, 90 (52.9\%) were male and $80(47.1 \%)$ were female. The age of the respondents ranged from 18 to 67 years with the mean age being $26.16 \pm 8.52$ years. On the basis of their occupation, maximum respondents 100 (64.1\%) were students, 38 (22.4\%) were doctors, and 23 (13.5\%) had other occupations.

The state-wise distribution of participants was as follows: among 170 participants, the maximum participants were from Delhi $(100,58.8 \%)$, followed by Himachal Pradesh (20, $11.8 \%)$, Bihar (10,5.9\%), Haryana (9, 5.3\%), Rajasthan (9, $5.3 \%)$, and Uttar Pradesh (9, 5.3\%). A small fraction of the respondents was from the states of Gujarat, Jharkhand, Karnataka, Maharashtra, Madhya Pradesh, and Punjab (Table 2).

Table 2.Demographic and Basic Characteristics of the Respondents

\begin{tabular}{|c|c|}
\hline Characteristics & Number (\%) \\
\hline \multicolumn{2}{|l|}{ Gender } \\
\hline Male & $90(52.9)$ \\
\hline Female & $80(47.1)$ \\
\hline \multicolumn{2}{|l|}{ Location } \\
\hline Delhi & $100(58.8)$ \\
\hline Himachal Pradesh & $20(11.8)$ \\
\hline Bihar & $10(5.9)$ \\
\hline Haryana & $9(5.3)$ \\
\hline Rajasthan & $9(5.3)$ \\
\hline
\end{tabular}




\begin{tabular}{|c|c|}
\hline Uttar Pradesh & $9(5.3)$ \\
\hline Others & $13(7.64)$ \\
\hline Occupation & $100(64.1)$ \\
\hline Student & $38(22.4)$ \\
\hline Doctor & $9(5.3)$ \\
\hline Service & $7(4.1)$ \\
\hline Self-employed & $6(3.5)$ \\
\hline Business & $1(0.6)$ \\
\hline Advocate & \\
\hline Source of income & $44(25.88)$ \\
\hline Salaried & $126(74.11)$ \\
\hline Non-salaried
\end{tabular}

Among 170 participants, 81 students were from Delhi, 7 students were from Rajasthan, 6 students were from Uttar Pradesh, 5 students were from Haryana and Himachal
Pradesh each, 2 students were from Bihar and 1 student was from Punjab and Chandigarh each. 15 doctors were from Delhi, 10 were from Himachal Pradesh, 4 were from Haryana, 2 were from Bihar and Gujarat each and 1 was from Chandigarh, Maharashtra, Madhya Pradesh, Rajasthan, and Uttarakhand each. A small proportion of respondents were from other states also (Table 3 ).

86 (61.0\%) participants of the age group between 18 and 30 years had no depression while 55 (39.0\%) participants had some degree of depression. 88 (62.4\%) participants of the age group between 18 and 30 years had no anxiety while $53(37.6 \%)$ participants had some degree of anxiety. 107 (75.9\%) participants of the age group between 18 and 30 Years had no stress while $24.10 \%$ of participants had some degree of stress (Table 4).

In the DASS-42 questionnaire, we found a significant difference ( $p$-value $<0.05$ ) between males and females in five questions. No significant difference was found for the rest of the questionnaire (Table 5).

Table 3. State-wise Distribution of Participants as per Their Occupation

\begin{tabular}{|c|c|c|c|c|c|c|c|}
\hline \multirow{2}{*}{ State } & \multicolumn{6}{|c|}{ Occupation } & \multirow{2}{*}{ Total } \\
\hline & Business & Student & Doctor & Self-employed & Advocate & Service & \\
\hline Bihar & 1 & 2 & 2 & 2 & 0 & 3 & 10 \\
\hline Chandigarh & 0 & 1 & 1 & 0 & 0 & 0 & 2 \\
\hline Delhi & 1 & 81 & 15 & 0 & 0 & 3 & 100 \\
\hline Gujarat & 0 & 0 & 2 & 0 & 0 & 0 & 2 \\
\hline Haryana & 0 & 5 & 4 & 0 & 0 & 0 & 9 \\
\hline Himachal Pradesh & 0 & 6 & 10 & 3 & 0 & 1 & 20 \\
\hline Jharkhand & 1 & 0 & 0 & 0 & 0 & 0 & 1 \\
\hline Karnataka & 1 & 0 & 0 & 0 & 0 & 0 & 1 \\
\hline Maharashtra & 0 & 0 & 1 & 0 & 0 & 0 & 1 \\
\hline Madhya Pradesh & 0 & 0 & 1 & 0 & 0 & 0 & 1 \\
\hline Punjab & 1 & 1 & 0 & 1 & 0 & 1 & 4 \\
\hline Rajasthan & 1 & 7 & 1 & 0 & 0 & 0 & 9 \\
\hline Uttar Pradesh & 0 & 6 & 0 & 1 & 1 & 1 & 9 \\
\hline Uttarakhand & 0 & 0 & 1 & 0 & 0 & 0 & 1 \\
\hline Total & 6 & 109 & 38 & 7 & 1 & 9 & 170 \\
\hline
\end{tabular}

Table 4.Distribution of Depression, Anxiety, and Stress between different Age Groups

\begin{tabular}{|c|c|c|c|c|c|}
\hline & Age (Years) & $\begin{array}{c}\text { Normal } \\
\mathbf{n}(\%)\end{array}$ & $\begin{array}{c}\text { Mild } \\
\mathbf{n}(\%)\end{array}$ & $\begin{array}{c}\text { Moderate } \\
\mathbf{n}(\%)\end{array}$ & $\begin{array}{c}\text { Severe } \\
\mathbf{n}(\%)\end{array}$ \\
\hline \multirow{3}{*}{ Depression } & $18-30$ & $86(61.0)$ & $17(12.1)$ & $24(17.0)$ & $14(9.9)$ \\
\cline { 2 - 6 } & $30-67$ & $16(55.2)$ & $4(13.8)$ & $7(24.1)$ & $2(6.9)$ \\
\hline \multirow{3}{*}{ Anxiety } & $18-30$ & $88(62.4)$ & $23(16.2)$ & $16(11.5)$ & $14(9.9)$ \\
\cline { 2 - 6 } & $30-67$ & $17(58.6)$ & $5(17.2)$ & $4(13.8)$ & $3(10.3)$ \\
\hline \multirow{2}{*}{ Stress } & $18-30$ & $107(75.9)$ & $12(8.5)$ & $18(12.8)$ & $4(2.8)$ \\
\cline { 2 - 6 } & $30-67$ & $21(72.4)$ & $4(13.7)$ & $2(6.9)$ & $2(6.9)$ \\
\hline
\end{tabular}


Table 5.Association between Gender and Five Questionnaire of DASS-42 on the Likert Scale

\begin{tabular}{|c|c|c|c|c|c|c|c|c|}
\hline $\begin{array}{l}\dot{0} \\
\text { v }\end{array}$ & $\begin{array}{l}\text { co } \\
\stackrel{0}{\check{y}} \\
\stackrel{0}{\partial}\end{array}$ & 於 & 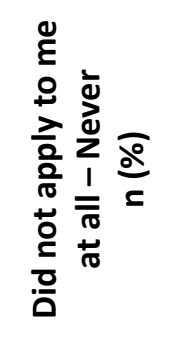 & 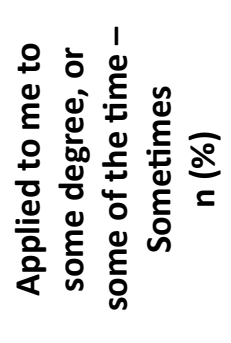 & 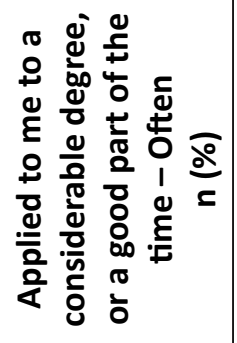 & 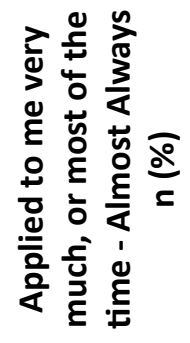 & $N_{\times} \frac{\frac{0}{T}}{\frac{\pi}{5}}$ & $\frac{0}{\frac{0}{0}}$ \\
\hline \multirow[b]{2}{*}{1.} & \multirow{2}{*}{$\begin{array}{l}\text { I found myself } \\
\text { getting upset by } \\
\text { quite } \\
\text { trivial (not } \\
\text { important) things. }\end{array}$} & Male & $34(37.77)$ & 34 (37.77) & $8(8.88)$ & $4(4.44)$ & \multirow[b]{2}{*}{11.251} & \multirow[b]{2}{*}{0.010} \\
\hline & & Female & $18(22.5)$ & $58(72.5)$ & $11(13.75)$ & $3(3.75)$ & & \\
\hline \multirow{2}{*}{2.} & \multirow{2}{*}{$\begin{array}{l}\text { I found myself } \\
\text { getting upset } \\
\text { rather easily. }\end{array}$} & Male & $33(36.66)$ & $33(36.66)$ & $11(12.22)$ & $3(3.33)$ & \multirow[t]{2}{*}{10.351} & \multirow[t]{2}{*}{0.016} \\
\hline & & Female & $17(21.25)$ & $51(63.75)$ & $16(20.00)$ & $6(7.5)$ & & \\
\hline \multirow[t]{2}{*}{3.} & \multirow{2}{*}{$\begin{array}{l}\text { I felt that I was } \\
\text { using a lot of } \\
\text { nervous energy. }\end{array}$} & Male & $40(44.44)$ & $24(26.66)$ & $11(12.22)$ & $5(5.55)$ & \multirow[t]{2}{*}{8.628} & \multirow[t]{2}{*}{0.035} \\
\hline & & Female & $28(35.00)$ & $46(57.50)$ & $12(15.00)$ & $4(5.00)$ & & \\
\hline \multirow[b]{2}{*}{4.} & \multirow{2}{*}{$\begin{array}{l}\text { I found it difficult } \\
\text { to tolerate } \\
\text { interruptions to } \\
\text { what I was doing. }\end{array}$} & Male & $33(36.66)$ & $22(24.44)$ & $19(21.11)$ & $6(6.66)$ & \multirow[b]{2}{*}{9.345} & \multirow[b]{2}{*}{0.025} \\
\hline & & Female & $29(36.25)$ & $42(52.50)$ & $10(12.50)$ & $9(11.25)$ & & \\
\hline \multirow[b]{2}{*}{5.} & \multirow{2}{*}{$\begin{array}{l}\text { I was intolerant of } \\
\text { anything that kept } \\
\text { me from getting } \\
\text { on with what I was } \\
\text { doing. }\end{array}$} & Male & $40(44.44)$ & $33(36.66)$ & $3(3.33)$ & $4(4.44)$ & \multirow[b]{2}{*}{8.377} & \multirow[b]{2}{*}{0.039} \\
\hline & & Female & $41(51.25)$ & $38(47.50)$ & $11(13.75)$ & $0(0.00)$ & & \\
\hline
\end{tabular}

Table 6.Distribution of Respondents according to Severity of Depression, Anxiety, and Stress assessed on DASS-42 Scale

\begin{tabular}{|c|c|c|c|}
\hline $\begin{array}{c}\text { Mental Wellbeing assessed } \\
\text { by DASS-42 Scale }\end{array}$ & $\begin{array}{c}\text { Depression } \\
\mathbf{n}(\%)\end{array}$ & $\begin{array}{c}\text { Anxiety } \\
\mathbf{n}(\%)\end{array}$ & $\begin{array}{c}\text { Stress } \\
\mathbf{n}(\%)\end{array}$ \\
\hline Normal & $102(60.0)$ & $105(61.8)$ & $128(75.3)$ \\
\hline Mild & $21(12.4)$ & $28(16.5)$ & $16(9.4)$ \\
\hline Moderate & $31(18.2)$ & $20(11.8)$ & $20(11.8)$ \\
\hline Severe & $13(7.6)$ & $10(5.9)$ & $5(2.9)$ \\
\hline Very severe & $3(1.8)$ & $7(4.1)$ & $1(0.6)$ \\
\hline TOTAL & $170(100)$ & $170(100)$ & $170(100)$ \\
\hline
\end{tabular}

DASS-42 was used to find out the level of mental wellbeing among respondents. Respondents who were considered normal by DASS-42 were significantly higher as compared to the respondents who were severe. In the case of level of depression, the number of cases considered normal $(102,60.0 \%)$ was much higher than the ones considered very severe $(3,1.8 \%)$. However, among the remaining respondents, 21 (12.4\%) had mild depression, and 31 (18.2\%) had moderate depression (Table 6).
The number of participants in severe and very severe categories was less, so we merged these under the severe category for statistical analysis to avoid an error. By applying Chi-square test, the association between depression and gender $\left(x^{2}=2.074, p\right.$-value $\left.=0.554\right)$ and the association between stress and gender $\left(x^{2}=4.258, p\right.$-value $\left.=0.235\right)$ were found to be not significant, while the association between anxiety and gender $\left(x^{2}=7.854, p\right.$-value $\left.=0.049\right)$, was found to be statistically significant (Table 7). 
Table 7.Scores of Depression, Anxiety, and Stress with Respect to Gender

\begin{tabular}{|c|c|c|c|c|c|c|c|c|}
\hline DASS-42 & & $\begin{array}{c}\text { Normal } \\
\mathrm{n}(\%)\end{array}$ & $\begin{array}{l}\text { Mild } \\
\mathrm{n}(\%)\end{array}$ & $\begin{array}{c}\text { Moderate } \\
\mathrm{n}(\%)\end{array}$ & $\begin{array}{c}\text { Severe } \\
\mathrm{n}(\%)\end{array}$ & $\begin{array}{l}\text { Total } \\
\text { n (\%) }\end{array}$ & $x^{2}$ value & p-value \\
\hline \multirow{2}{*}{ Depression } & Male & $\begin{array}{c}50 \\
(62.50)\end{array}$ & $\begin{array}{c}7 \\
(8.80)\end{array}$ & $\begin{array}{c}16 \\
(20.00)\end{array}$ & $\begin{array}{c}7 \\
(8.80)\end{array}$ & $\begin{array}{c}80 \\
(100)\end{array}$ & \multirow{2}{*}{2.074} & \multirow{2}{*}{0.554} \\
\hline & Female & $\begin{array}{c}52 \\
(57.80)\end{array}$ & $\begin{array}{c}14 \\
(15.60)\end{array}$ & $\begin{array}{c}15 \\
(16.70)\end{array}$ & $\begin{array}{c}9 \\
(10.00)\end{array}$ & $\begin{array}{c}90 \\
(100)\end{array}$ & & \\
\hline \multirow{2}{*}{ Anxiety } & Male & $\begin{array}{c}54 \\
(67.40)\end{array}$ & $\begin{array}{c}7 \\
(8.80)\end{array}$ & $\begin{array}{c}12 \\
(15.00)\end{array}$ & $\begin{array}{c}7 \\
(8.80)\end{array}$ & $\begin{array}{c}80 \\
(100)\end{array}$ & \multirow{2}{*}{7.854} & \multirow{2}{*}{0.049} \\
\hline & Female & $\begin{array}{c}51 \\
(56.70) \\
\end{array}$ & $\begin{array}{c}21 \\
(23.30) \\
\end{array}$ & $\begin{array}{c}8 \\
(8.90)\end{array}$ & $\begin{array}{c}10 \\
(11.10)\end{array}$ & $\begin{array}{c}90 \\
(100)\end{array}$ & & \\
\hline \multirow{2}{*}{ Stress } & Male & $\begin{array}{c}59 \\
(73.80)\end{array}$ & $\begin{array}{c}11 \\
(13.80)\end{array}$ & $\begin{array}{c}7 \\
(8.80)\end{array}$ & $\begin{array}{c}3 \\
(3.80)\end{array}$ & $\begin{array}{c}80 \\
(100)\end{array}$ & \multirow{2}{*}{4.258} & \multirow{2}{*}{0.235} \\
\hline & Female & $\begin{array}{c}69 \\
(76.70)\end{array}$ & $\begin{array}{c}5 \\
(5.60)\end{array}$ & $\begin{array}{c}13 \\
(14.40)\end{array}$ & $\begin{array}{c}3 \\
(3.30)\end{array}$ & $\begin{array}{c}90 \\
(100)\end{array}$ & & \\
\hline
\end{tabular}

\section{Discussion}

The present work is an observational cross-sectional study that aims to investigate the level of depression, anxiety and stress among people during lockdown imposed in the COVID-19 pandemic. The present study is a contribution to the literature that provides evidence that COVID-19 affects mental health in terms of anxiety, stress and depression among people. There is no doubt that people are experiencing outrageous uneasiness because of this pandemic due to the fear of getting the infection and of seeing such countless people dying. This dread is additionally escalated due to significant changes to our daily lives during the lockdown. ${ }^{10}$ The coronavirus pandemic has brought enormous uncertainty among adolescents, particularly for those preparing for exams, expecting to begin college, finance managers, job seekers, and everyday compensation labourers. Preliminary evidence suggests that symptoms of anxiety and depression (16-28\%) and self-reported stress $(8 \%)$ are common psychological reactions to the COVID-19 pandemic, and may be associated with disturbed sleep. ${ }^{11}$ Some studies suggest that rates of depression in the general population might be 7 times higher during the COVID-19 outbreak. $^{12}$

The present study evaluated the effect of COVID-19 during lockdown-2 on mental wellbeing among 170 people of different age groups during the second wave of Coronavirus using the DASS-42 questionnaires. This scale helps to determine the level of depression, anxiety, and stress. The results show that severity (severe and very severe) level is more in the case of anxiety as compared to depression and stress. Other than the normal level, most of the people fall under the category of moderate depression $(31,18.2 \%)$, mild anxiety (28, 16.5\%), and moderate stress (20, 11.8\%). Findings of the DASS- 42 indicated a significant association between anxiety and gender. The level of mental wellbeing was related to the age factor. A significant association was found between males and females in five questions of DASS-42, but the results indicated no significant differences between the levels of depression, anxiety, and stress in men and women as shown in gender DASS- 42 cross-tabulation.

In this observational study, data were collected at the end of lockdown 2. In our sample, $40 \%$ of the people had some degree of depression, $38.2 \%$ of the people had some degree of anxiety, and $34.7 \%$ of the people had some degree of stress. The prevalence of severe cases of all categories was low. People had experience of the previous lockdown-1 and also of COVID-19. People believed that everything would be in control with time. People followed the proper COVID-19 guidelines and appropriate behaviour, so there was no significant difference in mental wellbeing in both men and women.

\section{Limitations of the Study}

The present research study has some limitations. Firstly, the results drawn from the current study were on the basis of a cross-sectional study and the sample size was also limited. It does not reflect the characteristics of the whole population. Since this is a cross-sectional analysis of the information created from Google Forms, the documented data are a depiction of smartphone users only. A constraint of the study is the inability to capture generalisable information reflecting genuine wellbeing looking for patterns, as just individuals with admittance to smartphones and great web network responded to the questionnaire.

\section{Conclusion}

The aim of the study was to assess mental wellbeing among the Indian population during lockdown-2 of the COVID-19 pandemic. During the second lockdown in India, 
the residents suffered from a moderate level of depression, moderate level of stress, and mild level of anxiety. Findings of the DASS-42 indicated a significant association between anxiety and gender. The incidence of depression, anxiety, and stress was found more among women as compared to men. The outbreak emphasises the need to pay more attention to the people belonging to the age group of 30-67 years to prevent and mitigate the psychological outcome of the pandemic. In the light of these findings, necessary support may be provided via a virtual support system and through awareness programmes on social media to reduce the psychological impact of the pandemic.

\section{Financial Support and Sponsorship: None}

\section{Conflict of Interest: None}

\section{References}

1. World Health Organization [Internet]. Mental wellbeing: resources for the public; [cited 2021 Sep 7]. Available from: https://www.who.int/news-room/featurestories/mental-well-being-resources-for-the-public

2. Gallegos A. WHO declares public health emergency for novel coronavirus. Medscape Medical News; 2020.

3. Zahoor H, Mustafa N. Mental well-being and loneliness among residents of Karachi during the second lockdown of COVID-19. Acta Sci Neurol. 2021;4:51-55.

4. Dar KA, Iqbal N, Mushtaq A. Intolerance of uncertainty, depression, and anxiety: examining the indirect and moderating effects of worry. Asian J Psychiatr. 2017;29:129-33. [PubMed] [Google Scholar]

5. Brooks SK, Webster RK, Smith LE, Woodland L, Wessely S, Greenberg N, Rubin GJ. The psychological impact of quarantine and how to reduce it: rapid review of the evidence. Lancet. 2020;395(10227):912-20. [PubMed] [Google Scholar]

6. Kruk ME, Freedman LP. Assessing health system performance in developing countries: a review of the literature. Health Policy. 2008 Mar;85(3):263-76. [PubMed] [Google Scholar]

7. Von Elm E, Altman DG, Egger M, Pocock SJ, Gøtzsche PC, Vandenbroucke JP; STROBE Initiative. The Strengthening the Reporting of Observational Studies in Epidemiology (STROBE) statement: guidelines for reporting observational studies. Int J Surg. 2014;12(12):14959. [PubMed]

8. World Health Organization [Internet]. Process of translation and adaptation of instruments; [cited 2021 Mar 19]. Available from: http://www.who.int/ substance_abuse/research_tools/translation/en/

9. Lovibond SH. Manual for the Depression Anxiety Stress Scales. 2nd ed. Sydney (Australia): Psychology Foundation; 1995.

10. Nazli T, Heena, Raheem A, Kishore J. Perceptions and Practices of the Adult Population in Response to SARS-
CoV-2 Pandemic in India. Epidem Int. 2020;5(2):10-16. [Google Scholar]

11. Rajkumar RP. COVID-19 and mental health: a review of the existing literature. Asian J Psychiatr. 2020;52:102066. [PubMed] [Google Scholar]

12. Bueno-Notivol J, Gracia-García P, Olaya B, Lasheras I, López-Antón R, Santabárbara J. Prevalence of depression during the COVID-19 outbreak: a metaanalysis of community-based studies. Int J Clin Health Psychol. 2021;21(1):100196. [PubMed] [Google Scholar] 